\title{
HAND HYGIENE IN PERITONEAL DIALYSIS PATIENTS: A COMPARISON OF TWO TECHNIQUES
}

\author{
Ana Elizabeth Figueiredo, ${ }^{1,2}$ Soraia Lemos de Siqueira, ${ }^{2}$ Carlos Eduardo Poli-de-Figueiredo, ${ }^{2}$ \\ and Domingos 0. d'Avila
}

\section{School of Nursing, Physiotherapy and Nutrition, ${ }^{1}$ and Postgraduate Program in Medicine and Health Sciences, School of Medicine, ${ }^{2}$ Pontificia Universidade Católica do Rio Grande do Sul, Porto Alegre, Brazil}

- Introduction and Objectives: Hand hygiene is essential for preventing peritoneal dialysis (PD)-related infections. The present study compared the effectiveness of two hygiene techniques in reducing the number of colony-forming units (CFUs) on the hands of patients undergoing PD.

- Methods: In this controlled clinical trial, 22 participants enrolled in the same PD program underwent a two-hand evaluation for microbiologic flora. Participants participated in two treatments: a) simple hand hygiene plus antiseptic hand hygiene, in which the patients washed their hands with water and glycerin soap for 1 minute and then rubbed and dried their hands with $70 \%$ ethyl alcohol gel; and b) antiseptic hand hygiene, in which the patients rubbed their hands with $70 \%$ ethyl alcohol gel until fully dry. To sample distal finger surfaces, we asked the participants to touch sheep blood agar plates directly.

- Results: The CFU count for both hands was significantly higher in the regular hygiene group than in the gel-only group [69.0 (16.0 - 101.0) CFU vs 9.0 (2.2 - 55.5) CFU, $p<0.010]$. Growth of coagulase-negative Staphylococcus colonies was significantly higher in right-hand cultures from the regular hygiene group than in those from the gelonly group [69.5 (26.25 - 101.0) CFU vs $9.5(1.0-41.7)$ CFU; $p<0.050]$.

- Conclusions: Among patients undergoing PD, using 70\% ethyl alcohol gel to cleanse the hands may be more effective than following the regular hygiene recommendations in reducing bacterial populations.

Perit Dial Int 2013; 33(6):655-661 www.PDIConnect.com epub ahead of print: 31 0ct 2013 doi:10.3747/pdi.2012.00298

KEYWORDS: Handwashing; chronic renal disease; hand hygiene; alcohol hand rub.

Correspondence to: A.E. Figueiredo, Rua Miracema, 407, Chácara das Pedras, Porto Alegre, RS 91330490, Brazil.

anaef@pucrs.br

Received 4 November 2012; accepted 30 January 2013
Tn terms of the number of patients undergoing dialysis

1 worldwide, Brazil ranks third, with more than 92000 patients currently on renal replacement therapy. Yet only $9.4 \%$ of those patients make use of peritoneal dialysis (PD) $(1,2)$.

Infectious complications such as peritonitis, often associated with unhygienic technique and exit-site infection, are still the "Achilles heel" of PD and have been the major cause of transfer from PD to another therapy (3). In a Brazilian multicenter survey, death from cardiovascular causes was the main reason for PD discontinuation, followed by peritonitis (4). In the same study, the prevalence of peritonitis was 1 episode in 30 patient-months, mostly caused by Staphylococcus aureus and coagulase-negative Staphylococcus (CNS), although large regional differences were found. The prevalence of exit-site infection was 1 episode in 54 patient-months, with negative cultures in almost $40 \%$ of cases (4-6). Preventing such complications, largely associated with skin-resident microbes such as $S$. aureus and CNS, requires special attention (7).

Hand hygiene $(\mathrm{HH})$ has been recognized worldwide as a primary and significant measure for controlling health care-related infections, and it is also a key factor in the prevention and control of contagion within health services. With good $\mathrm{HH}$, morbidity and mortality rates fall (8). The World Health Organization (WHO) has made significant investments in awareness campaigns, emphasizing the importance of HH practices $(9,10)$. Use of an effective topical antimicrobial agent, coupled with proper technique, is central to preventing hand transmission of microorganisms (11, pp. 1052-68).

As result of its increased scope of use, "hand hygiene" has replaced "handwashing" in terms of vocabulary, as in a recent Hand Hygiene Task Force publication (12). The new term encompasses techniques ranging from simple cleansing with water and soap (with or without an antimicrobial agent), through antiseptic hygiene (with 
friction-based antiseptic alcohol or other substances), to surgical hand antisepsis. Hand hygiene techniques are recommended for health care professionals and are not specifically intended for PD patients $(8,12-14)$. Handwashing has been mostly considered a matter of personal hygiene; however, for patients undergoing $\mathrm{PD}$, it is a key procedure. Adherence to a specific $\mathrm{HH}$ technique is vital to the success of the therapy (15). In a previous study, approximately $51 \%$ of patients who had been taught a handwashing technique at the start of therapy were no longer using it after 6 months on PD (16).

From the inception of PD therapy, several $\mathrm{HH}$ techniques have been proposed for use by PD patients before a bag change or cycler connection and disconnection. Among them are washing the hands with water and non-antimicrobial soap for 3 - 5 minutes; washing with water and soap, followed by application of an alcoholbased product; washing with an antimicrobial soap; and rubbing the hands with an alcohol-based product (15). A $70 \%$ alcohol gel or a $70 \%$ alcohol solution with $1 \%-3 \%$ glycerin may replace washing with water and soap if the hands are not obviously dirty $(8,13,14)$. The Brazilian Health Surveillance Agency, ANVISA, says that ethanol, recommended since 1888 , is one of the most commonly used antimicrobial agents in Brazil (14).

Approximately $42 \%$ of peritonitis episodes are known to be associated with touch contamination and are linked to a Staphylococcus species (15). Peritoneal dialysis programs should do all they can to reduce the incidence of peritonitis. At one time, the International Society for Peritoneal Dialysis (ISPD) recommended handwashing with water and antimicrobial soap as standard care, and that procedure is still followed in many PD centers (3). However, the newer ISPD guidelines suggest that washing and drying of the hands, followed by use of a disinfectant, should be emphasized when patients are taught $\mathrm{HH}$, especially in areas in which the water supply is unreliable. Still, the ISPD guidelines do not suggest or promote specific techniques (7).

The 2009 revised WHO guidelines suggest that the procedure for washing hands with water and soap should be extended to $40-60$ seconds, followed by thoroughly drying. Alternatively, hands should be rubbed with an alcohol-based mixture for 20 - 30 seconds (9). Another recommendation is to rub the hands with an alcoholbased liquid till dry after washing with water and soap (9). It is common knowledge that the guidelines were developed for health care professionals in hospitals and outpatient clinics $(9,12,14)$. So far, no specific or indepth studies have evaluated the effect of $\mathrm{HH}$ technique on bacterial populations, particularly in PD patients.
The aim of the current study was to compare the efficacy of two $\mathrm{HH}$ techniques in reducing the number of colony-forming units (CFUs) on the hands of PD patients.

\section{METHODS}

The present study is part of the Infections in Peritoneal Dialysis Project approved by the Research Ethics Committee of Pontifícia Universidade Católica do Rio Grande do Sul (PUCRS) (Protocol 09/04535). This controlled clinical trial enrolled 22 patients with end-stage renal disease who were undergoing PD at the nephrology dialysis unit at the university hospital (Hospital São Lucas da PUCRS). To be included, patients had to be 18 years of age or older and stable on PD treatment for at least 1 month; they also had to agree to participate by signing an informed consent form. Patients hospitalized during the assessment period were excluded.

\section{SAMPLE COLLECTION TECHNIQUE}

To obtain samples for culture, we had all patients gently touch the surface of sheep blood agar plates (bioMérieux Brasil, Rio de Janeiro, Brazil) with the distal sides of their right and left fingertips. We collected samples in two stages, during scheduled appointments on different days, in a secluded area used by the PD program. We informed all patients about the nature of each technique before starting the process, and all patients received identical training for reducing the risk of $P D$ infections $(17,18)$. We evaluated HH efficacy in relation to transient and resident flora (S. aureus and CNS) after application of the two $\mathrm{HH}$ techniques already in use.

First Collection: For the first collection, PD patients performed simple hand hygiene ( $\mathrm{SHH}$ ) followed by antiseptic hand hygiene $(\mathrm{AHH})$. For $\mathrm{SHH}$, the patients wetted both hands under running tap water and applied plenty of soap, without touching the sink. They rubbed both hands together palm to palm and then one palm against the back of the opposite hand and vice versa, including rubbing between the fingers. In addition, they rubbed the fingertips and nails of the left hand in a circular motion against the cupped palm of the right hand and vice versa. The entire washing procedure lasted no less than 1 minute. The patients rinsed their hands one at a time under running water to remove all soap residues and then dried their hands with paper towels. Avoiding direct hand contact with the taps was strongly recommended, and so the patients always used paper towels to turn off the water. Finally, for $\mathrm{AHH}$, the patients rubbed a $3 \mathrm{~mL}$ 
measure of $70 \%$ ethyl alcohol gel over all surfaces of their hands until the gel evaporated, using the same motions as for the soap-and-water washing.

Second Collection: The second collection was taken after $\mathrm{AHH}$ alone. In this procedure, $\mathrm{PD}$ patients applied $3 \mathrm{~mL}$ of $70 \%$ ethyl alcohol gel to the palm of one hand and rubbed both palms together $(8,13)$. They then rubbed the palm of their right hand against the back of the left hand, interlacing the fingers, and vice versa. They rubbed the backs of the fingers of one hand against the palm of the opposite hand with fingers interlocked, and vice versa. They also clasped the right thumb in the palm of their left hand and vice versa, applying friction rotationally. Finally, they rubbed the fingertips and nails of the left hand in a circular motion against the palm of the right hand, and vice versa. They continued this friction until their hands were totally dry. Paper towels were not used. The amount of alcohol gel the patients applied allowed for complete evaporation in $20-60$ seconds.

The motions that the patients used for both procedures-washing their hands with water and soap and rubbing them with alcohol gel-were those recommended by WHO in its 2009 revised guidelines (9).

Because a previous study conducted in the same dialysis unit at Hospital São Lucas da PUCRS demonstrated that the CFU counts in cultures obtained from hands before $\mathrm{HH}$ were not significantly different from those collected after $\mathrm{SHH}$, we decided not to collect samples before HH (19). The composition of the hand gel (Prolim Química Avançada, Taubaté, Brazil) used for AHH was $70 \%$ ethyl alcohol, ethanol, isopropanol, propylene glycol, acrylic thickener, emollient, and water. We chose a high-foaming liquid soap (Adhetech Química Indústria e Comércio, Sumaré, Brazil) for the $\mathrm{SHH}$ procedure. Its composition was cocamidopropyl betaine, polyethylene glycol distearate, methylchloroisothiazolinone, lauryl ether sulfate, anise essence, glycerin, citric acid, and water.

\section{CULTURES}

After the blood agar plates were seeded, they were incubated at $37^{\circ} \mathrm{C}$ for 48 hours (20), and after bacteria growth, the CFUs were counted. We used a coagulase test to verify the presence of predetermined bacteria, and rabbit plasma to identify genera; Gram staining was subsequently used to identify bacteria. Both tests were conducted in the Microbiology Laboratory of the Hospital São Lucas da PUCRS. Before counting started, we decided to consider only the CFUs of $S$. aureus and CNS, the germs most frequently associated with bacterial peritonitis $(4,6,21,22)$.

\section{STATISTICAL ANALYSIS}

Categorical variables are presented as absolute and relative frequencies, and continuous variables, as means (standard deviation) or medians (interquartile range). We used the Kolmogorov-Smirnov test to evaluate distribution symmetry, the Mann-Whitney U-test to compare two independent groups of continuous variables, the Wilcoxon test to compare paired groups, and the Spearman rank correlation coefficient to evaluate relationships between continuous variables. The SPSS software application (version 17.0 for Windows: SPSS, Chicago, IL, USA) was used throughout. We adopted a value of $p \leq 0.050$ for statistical significance.

\section{RESULTS}

Of the 22 patients enrolled, $54.5 \%(n=12)$ were men. The mean age of the study population was $50.3 \pm$ 16 years (range: $21-76$ years). Median time on dialysis was 23.5 months (range: 1.9 - 75.0 months). We found a similar distribution for continuous ambulatory PD and automated PD: $54.5 \%(n=12)$ and $45.5 \%(n=10)$ respectively. The median interval between individual sample collections was 11 days (range: 1 - 62 days).

We noted a significant difference between the two $\mathrm{HH}$ techniques when the number of CFUs from both hands were compared: 69.0 (range: 16.0 - 101.0) for SHH+AHH versus 9.0 (range: $2.2-55.5)$ for $\mathrm{AHH}(p<$ 0.010 ). The most prevalent microorganism was CNS (S. aureus occurred in only 2 cultures), and so only CNS CFUs were counted.

Table 1 compares the growth of CNS colonies from the right and left hands for each technique. Considering right hands only, growth of CNS colonies was significantly higher in the $\mathrm{SHH}+\mathrm{AHH}$ group than in the $\mathrm{AHH}$ group: 69.5 CFUs (range: 26.25 - 101.0 CFUs) versus 9.5 CFUs (range: $1.0-41.7$ CFUs) respectively $(p<0.050)$.

Figure 1 illustrates the growth of CNS from both hands after the use of each $\mathrm{HH}$ method. No difference in the growth of CNS was detected by sex or type of dialysis (data not shown). Table 2 depicts the correlation of age and time on dialysis with CNS growth, and Figure 2, of age with CNS growth. Bacterial growth from both hands was moderate and positively correlated with age in both groups (SHH+AHH: $r=0.365, p<0.050 ; \mathrm{AHH}: r=0.315$, $p<0.050)$.

\section{DISCUSSION}

Our study evaluated two $\mathrm{HH}$ techniques, demonstrating that the use of alcohol gel alone adequately reduces 
TABLE 1

Mean, Median, and Standard Deviation for Coagulase-Negative Staphylococci by Hand Hygiene Technique

\begin{tabular}{|c|c|c|c|c|c|c|c|}
\hline \multirow[b]{3}{*}{ Variable } & \multicolumn{6}{|c|}{ Hand hygiene technique } & \multirow{3}{*}{$\begin{array}{c}p \\
\text { Value }\end{array}$} \\
\hline & \multicolumn{3}{|c|}{ Simple plus antiseptic } & \multicolumn{3}{|c|}{ Antiseptic alone } & \\
\hline & Mean & $S D$ & Median & Mean & SD & Median & \\
\hline Right hand & 61.9 & 45.2 & 85.5 & 25.8 & 37.2 & 8.0 & 0.007 \\
\hline Left hand & 57.2 & 41.7 & 44.0 & 37.8 & 42.6 & 16.5 & 0.054 \\
\hline$p$ Value $\mathrm{e}^{\mathrm{a}}$ & & & 0.530 & & & 0.132 & \\
\hline TOTAL & 59.6 & 43.1 & 69.0 & 31.8 & 39.9 & 9.0 & 0.002 \\
\hline
\end{tabular}

$\mathrm{SD}=$ standard deviation.

a By Wilcoxon test.

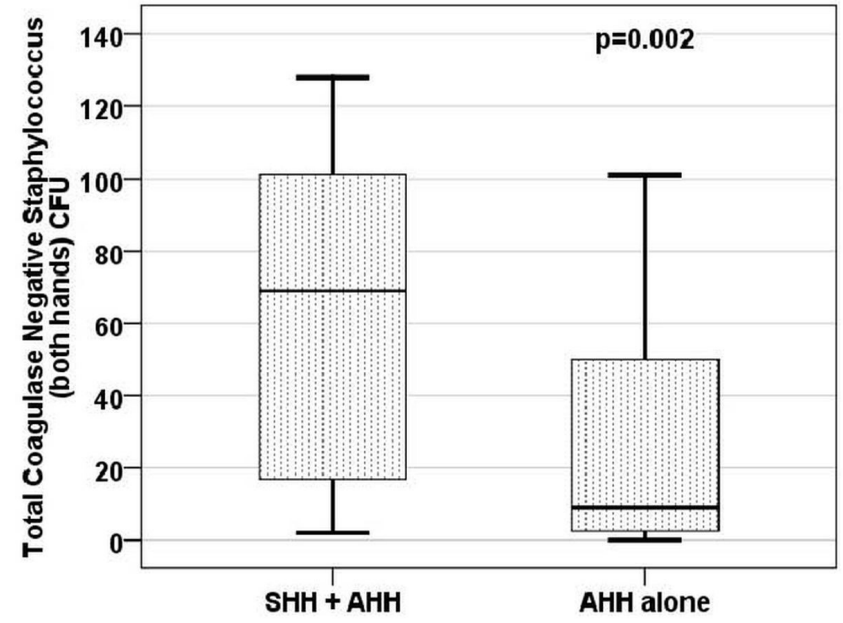

Figure 1 - Colony-forming units (coagulase-negative Staphylococcus, both hands). Statistical significance was evaluated using the Wilcoxon test. $\mathrm{SHH}=$ simple hand hygiene; $\mathrm{AHH}=$ antiseptic hand hygiene.

the number of bacteria on the hands of patients undergoing PD. Interestingly, the efficiency of that technique was reduced when it was immediately preceded by $\mathrm{SHH}$. The characteristics of the study population were similar to those of other Brazilian and Latin American PD populations with regard to sex and age, but the prevalence of users of automated PD was higher in our study $(2,4,23-25)$.

Previous studies comparing the antimicrobial efficacy of alcohol gel or liquid with that of a non-antimicrobial soap for handwashing demonstrated that alcohol gel alone significantly reduced $(>99.9 \%)$ colonization by transient bacteria $(10,25,26)$. In CNS counts, the number of CFUs from both hands was significantly higher after $\mathrm{SHH}+\mathrm{AHH}$. The interference of moisture or the effect of persistent hand humidity after alcohol action could explain such a difference. In general, antimicrobial activity increases in parallel with the size of the alcohol carbon chain, even though water solubility diminishes (10). Only aliphatic alcohols that are completely water-miscible (preferably ethanol, isopropanol, and n-propanol) have been used as HH components (10;11, pp. 1727-46). Further evidence suggests that the efficacy of alcohol preparations may be affected by diverse factors such as type, concentration, contact time, friction, and volume used, independently of the hands being wet or not at the time of exposure $(8 ; 12 ; 11$, pp. 1727-46;27).

The US Centers for Disease Control have stated that alcohols possess antimicrobial activity in vivo, effectively reducing the bacterial population on hands (12). Typically, the log reduction in bacterial load for hands artificially contaminated with bacteria is, on average, $3.5 \log _{10}$ after 30 seconds' application and $4.0-5.0 \log _{10}$ after 1 minute. In addition, alcohols have in vitro germicidal activity against gram-positive and gram-negative vegetative bacteria (12). The perceived correlation between age and number of CNS CFUs may be the result of a sensitivity bias determined by sample size. Another factor may be the vulnerability of the hands of elderly people to colonization by temporarily resident microbiota (micro-organisms from the transient skin flora, detected for longer periods and multiplying without harming the host). Changes in skin permeability and decreased sebaceous secretion in older people may explain those findings (11, pp. 1052-68). The same skin changes may encourage the presence of Streptococcus species, gram-negative enteric bacilli, fungi, and gram-positive bacteria, not all of which form part of the permanent microbiota (11, pp. 1052-68;12), but which can be found in the anterior nares, axillae, groin, and perineal region at ratios that vary from $10 \%$ to $30 \%$ (11, pp. 1052-68;12). The number of germs (S. aureus, Proteus mirabilis, etc.) quantified on intact skin in certain patients may vary in the range $10^{2}-10^{6} / \mathrm{cm}^{2}(11$, pp. 1052-68;12). People with diabetes mellitus and dialysis patients have an increased probability of intact skin colonization by $S$. aureus (11, pp. 1052-68;12). 
TABLE 2

Spearman Correlation ${ }^{\mathrm{a}}$ of Age and Time on Dialysis with Coagulase-Negative Staphylococci (CNS) Colony Growth

\begin{tabular}{llcccr} 
& & \multicolumn{3}{c}{ Hand hygiene technique } \\
& \multicolumn{1}{c}{ Correlation variables } & Simple plus antiseptic & Antiseptic alone \\
& & $R$ & $p$ Value & $R$ & $p$ Value \\
\hline \multirow{2}{*}{ Age (years) } & CNS growth right hand & 0.398 & 0.066 & 0.378 & 0.083 \\
& CNS growth left hand & 0.328 & 0.146 & 0.286 & 0.198 \\
\multirow{3}{*}{ Time on dialysis (months) } & CNS growth total & 0.365 & 0.016 & 0.315 & $\mathbf{0 . 0 3 7}$ \\
& CNS growth right hand & -0.086 & 0.703 & 0.045 & 0.843 \\
& CNS growth left hand & 0.369 & 0.099 & -0.054 & 0.812 \\
& CNS growth total & 0.118 & 0.451 & -0.013 & 0.934 \\
\hline
\end{tabular}

${ }^{\text {a }}$ Boldface type indicates significance.

(A)

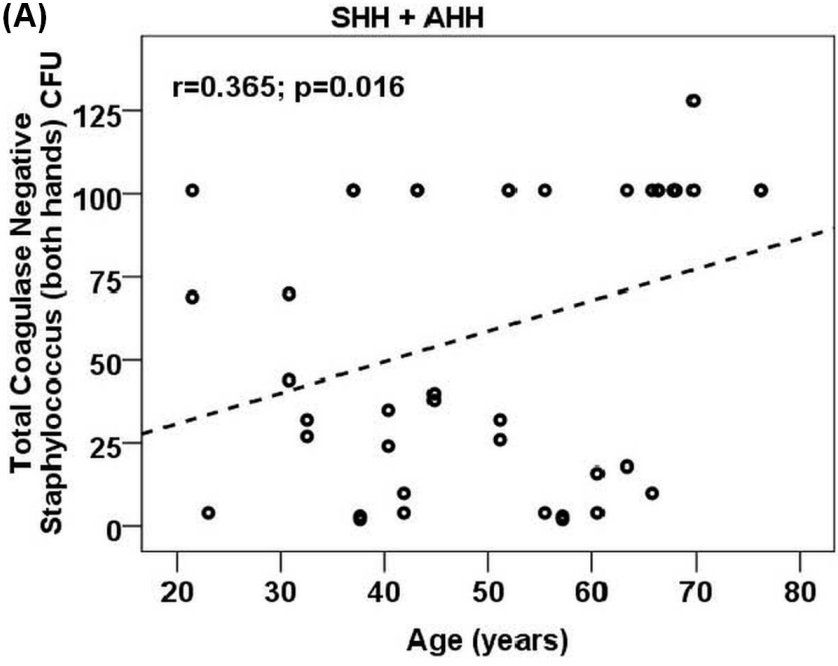

(B)

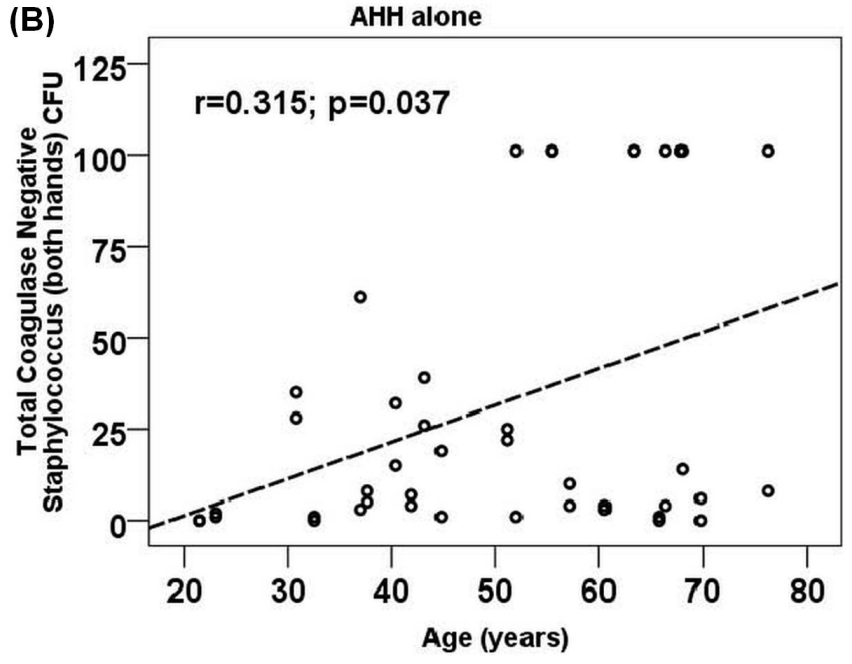

Figure 2 - Correlation between age and total number of colony-forming units (coagulase-negative Staphylococcus, both hands), bivariate correlation. $\mathrm{SHH}=$ simple hand hygiene; $\mathrm{AHH}=$ antiseptic hand hygiene.

In the present study, no correlation between treatment follow-up time and the number of CNS CFUs was detected. Previous studies have shown that chronic disease, the need for continuous treatment for extended periods, advanced age, and the presence of comorbidities reduce quality of life $(28,29)$. Patients on PD share many of those characteristics, rendering them more vulnerable to complications by reducing their ability to comply with treatment protocols, including HH proficiency (29).

Peritonitis is a serious complication of PD therapy and a major cause of technique failure and death. Worldwide, gram-positive cocci have been the main agents of bacterial peritonitis, CNS being the more frequently identified micro-organism $(3-7,19,29-32)$. Despite being responsible for only a small proportion of peritonitis episodes in many countries, $S$. aureus has been the main agent of PD peritonitis in some Latin American countries, particularly Brazil $(6,32)$. That finding may be associated with the high proportion (40\%) of negative cultures, which might conceal bacterial species such as CNS (4). Yet, contrary to Brazilian data overall (4-6), CNS has been the dominant micro-organism in PD peritonitis episodes in our center, with approximately $10 \%$ negative cultures (21).

A randomized study evaluated the comparative efficacy of rubbing the hands with an alcohol-based solution to reduce contamination and of washing with an antimicrobial soap. Bacterial counts were reduced in both groups after $\mathrm{HH}$; however, for each participant, the reduction of the mean bacterial contamination was significantly greater after alcohol application and rubbing than after handwashing with antimicrobial soap ( $83 \%$ vs $58 \%$ respectively, $p=0.0012$ ) (10). In addition, alcohol use and handwashing with water and soap were evaluated by comparing digital impressions of the dominant hand before and after $\mathrm{HH}$. Washing with water and soap resulted in only a $30 \%$ reduction, significantly 
less than was seen with various alcohol formulations $(10,34)$. In the present study, the mean CFU count was significantly higher for the $\mathrm{SHH}+\mathrm{AHH}$ group than for the $\mathrm{AHH}$ group, indicating that $\mathrm{SHH}$ should not be performed before $\mathrm{AHH}$. Used alone, $70 \%$ ethyl alcohol in gel form is effective in reducing the number of CFUs cultured from treated hands. It also reduces and simplifies the $\mathrm{HH}$ procedure, which may induce patients to adhere to it before they perform a PD bag exchange. It has been said that to keep PD patients in long-term therapy, specific support and continuous education are mandatory $(3,17,35,36)$. Programs to increase patient awareness and involvement may be effective in increasing adherence to $\mathrm{HH}$ practices.

We acknowledge the potential limitations of our study. The sequence of $\mathrm{HH}$ was not randomized. Colonization by CNS before HH was evaluated in a previous study (19). Different species of CNS were not evaluated, and despite the reduction of CNS colonization with $\mathrm{AHH}$, changes in hand flora leading to more pathogenic strains of CNS cannot be excluded. Additional studies to replicate the current results are needed to induce change in standard practices. Characterizing CNS strains over a prolonged treatment period or confirming that the rate of $\mathrm{PD}$-related infection is lower in patients randomized to $\mathrm{AHH}$ alone than to $\mathrm{SHH}+\mathrm{AHH}$ may be necessary. Some other limitations cannot be disregarded: sociocultural influences and patient dependence on caregivers may have represent drawbacks (13).

Because they are effective and easy to use, alcoholbased formulations have been indicated as substances of choice for $\mathrm{HH}$ if the hands are not visibly soiled. In addition to reducing the number of microbes, they take less time to apply and cause less skin irritation than handwashing with water and soap, antiseptic or not $(8,12)$. They are available everywhere, although they are a little more expensive. Finally, experimental and non-experimental evidence suggest that $\mathrm{HH}$ is associated with a decline in infection risk overall, being more effective than any other known control practice (36).

\section{CONCLUSIONS}

Our study demonstrates that rubbing the hands with $70 \%$ ethyl alcohol gel is more effective than the usually recommended procedure for reducing the number of remaining micro-organisms. Substituting an alcohol gel preparation for SHH may be a better option for PD patients. However, the time spent washing or rubbing the hands requires attention, because both hands must be equally cared for.

\section{ACKNOWLEDGMENT}

CEPF is a Conselho Nacional de Desenvolvimento Cientifico e Tecnologico researcher.

\section{DISCLOSURES}

AEF was a member of the Regional Advisory Board for Baxter Healthcare Corporation for Latin America (2011-2012). CEPF and DOA are researchers of the University Hospital Clinical Research Center. SLS declares no financial conflict of interest.

\section{REFERENCES}

1. Pecoits-Filho $R$, Abensur $H$, Cueto-Manzano AM, Dominguez J, Divino Filho JC, Fernandez-Cean J, et al. Overview of peritoneal dialysis in Latin America. Perit Dial Int 2007; 27:316-21.

2. Sesso RC, Lopes AA, Thomé FS, Lugon JR, Santos DR. Report of the Brazilian census dialysis 2010. J Bras Nefrol 2011; 33:442-7.

3. Piraino B, Bailie GR, Bernardini J, Boeschoten E, Gupta A, Holmes C, et al. on behalf of the ISPD Ad Hoc Advisory Committee. Peritoneal dialysis-related infections recommendations: 2005 update. Perit Dial Int 2005; 25:107-31.

4. Fernandes N, Bastos MG, Cassi HV, Machado NL, Ribeiro $J A$, Martins $G$, et al. on behalf of the Brazilian Peritoneal Dialysis Multicenter Study. The Brazilian Peritoneal Dialysis Multicentric Study Group (BRAZPD): characterization of the cohort. Kidney Int Suppl 2008; 73:S145-51.

5. Pecoits-Filho RFS, Pasqual DD, Fuerbringer R, Sauthier SM, Riella MC. Continuous ambulatory peritoneal dialysis (CAPD): experience of 15 years in Curitiba [Portuguese]. $J$ Bras Nefrol 1998; 20:22-30.

6. Barretti P, Moraes TM, Camargo CH, Caramori JC, Mondelli AL, Montelli AC, et al. Peritoneal dialysis-related peritonitis due to Staphylococcus aureus: a single-center experience over 15 years. PLoS One 2012; 7:e31780.

7. Li PK, Szeto CC, Piraino B, Bernardini J, Figueiredo AE, Gupta A, et al. on behalf of the International Society for Peritoneal Dialysis. Peritoneal dialysis-related infections recommendations: 2010 update. Perit Dial Int 2010; 30:393-423. [Erratum in: Perit Dial Int 2011; 31:512]

8. World Health Organization (WHO). The WHO Guidelines on Hand Hygiene in Health Care (advanced draft). Global Patient Safety Challenge 2005-2006: Clean Care Is Safer Care. Geneva, Switzerland: WHO Press; 2006.

9. World Health Organization (WHO). WHO Guidelines on Hand Hygiene in Health Care (revised Aug 2009). First Global Patient Safety Challenge: Clean Care Is Safer Care. Geneva, Switzerland: WHO Press; 2009.

10. Girou E, Loyeau S, Legrand P, Oppein F, Brun-Buisson C. Efficacy of handrubbing with alcohol based solution versus standard handwashing with antiseptic soap: randomised clinical trial. BMJ 2002; 325:362. 
11. Rotter ML. Hand washing and hand disinfection. In: Mayhall CG, ed. Hospital Epidemiology and Infection Control. Baltimore, MD: Williams and Wilkins; 1996.

12. Boyce JM, Pittet D, eds. Guideline for Hand Hygiene in Health-Care Settings: Recommendations of the Healthcare Infection Control Practices Advisory Committee and HICPAC/ SHEA/APIC/IDSA Hand Hygiene Task Force. Thorofare, NJ: Slack; 2002: 104-6.

13. Boyce JM, Pittet $D$ on behalf of the Healthcare Infection Control Practices Advisory Committee; HICPAC/SHEA/ APIC/IDSA Hand Hygiene Task Force. Guideline for hand hygiene in health-care settings. Recommendations of the Healthcare Infection Control Practices Advisory Committee and the HICPAC/SHEA/APIC/IDSA Hand Hygiene Task Force. Society for Healthcare Epidemiology of America/ Association for Professionals in Infection Control/Infectious Diseases Society of America. MMWR Recomm Rep 2002; 51:1-45.

14. ANVISA-Brasil, Ministry of Health, National Agency for Sanitation Vigilance. Hand Hygiene in Health Services [Portuguese]. Brasília, Brazil: ANVISA; 2007.

15. Firanek C, Guest S. Hand hygiene in peritoneal dialysis. Perit Dial Int 2011; 31:399-408.

16. Dong J, Chen Y. Impact of the bag exchange procedure on risk of peritonitis. Perit Dial Int 2010; 30:440-7.

17. Bernardini J, Price V, Figueiredo A on behalf of the International Society for Peritoneal Dialysis (ISPD) Nursing Liaison Committee. Peritoneal dialysis patient training, 2006. Perit Dial Int 2006; 26:625-32.

18. Piraino B, Bernardini J, Brown E, Figueiredo A, Johnson DW, Lye WC, et al. ISPD position statement on reducing the risks of peritoneal dialysis-related infections. Perit Dial Int 2011; 31:614-30.

19. Siqueira $S L$, Figueiredo $A E$, Poli de Figueiredo $C E$, D'Avila D0. Comparing two hand hygiene techniques for peritoneal dialysis (PD) patients. J Bras Nefrol 2012; 34:355-60.

20. Murray PR, Baron EJ, Jorgensen JH, Landry ML, Pfaller MA, eds. Manual of Clinical Microbiology. 9th ed. Washington, DC: ASM Press; 2007.

21. Figueiredo $A E$, Poli de Figueiredo CE, d'Avila D0. Peritonitis prevention in CAPD: to mask or not? Perit Dial Int 2000; 20:354-8.

22. Lee HY, Choi HY, Park HC, Seo BJ, Do JY, Yun SR, et al. Changing prescribing practice in CAPD patients in Korea: increased utilization of low GDP solutions improves patient outcome. Nephrol Dial Transplant 2006; 21:2893-9.

23. Cusumano A, Garcia GG, Di Gioia C, Hermida 0, Lavorato $C$ on behalf of the Latin American Registry of Dialysis and Transplantation. The Latin American Dialysis and Transplantation Registry (RLDT) annual report 2004. Ethn Dis 2006; 16(Suppl 2):S2-10-13.

24. Correa-Rotter R. APD in the developing world: is there a future? Semin Dial 2002; 15:385-7.

25. Lindley EJ, De Vos JY, Morgan I, Murcutt G, Hoenich N, Polaschegg $\mathrm{H}$, et al. On line UV-adsorbance measurements. Summary of the EDTNA/ERCA journal club discussion. Summer 2006. J Ren Care 2007; 33:41-8.

26. Kawagoe JY. Hand Hygiene: Comparison of the Antimicrobial Efficacy of Alcohol-Gel and Liquid Formulation-Hands with Organic Matter [Thesis, Portugese]. São Paulo, Brazil: School of Nursing, University of São Paulo; 2004.

27. Kampf G, Kramer A. Epidemiologic background of hand hygiene and evaluation of the most important agents for scrubs and rubs. Clin Microbiol Rev 2004; 17:863-93.

28. Grincenkov FRS, Fernandes N, Chaoubah A, Bastos K, Qureshi AR, Pécoits-Filho $R$, et al. Factors associated with quality of life in patients on peritoneal dialysis incidents in Brazil (BRAZPD). J Bras Nefrol 2011; 33:38-44.

29. Chow KM, Szeto CC, Leung CB, Law MC, Li PK. Impact of social factors on patients on peritoneal dialysis. Nephrol Dial Transplant 2005; 20:2504-10.

30. Mujais S. Microbiology and outcomes of peritonitis in North America. Kidney Int Suppl 2006; 70:S55-62.

31. Kim DK, Yoo TH, Ryu DR, Xu ZG, Kim HJ, Choi KH, et al. Changes in causative organisms and their antimicrobial susceptibilities in CAPD peritonitis: a single center's experience over one decade. Perit Dial Int 2004; 24:424-32.

32. Barretti P, Bastos KA, Dominguez J, Caramori JC. Peritonitis in Latin America. Perit Dial Int 2007; 27:332-9.

33. Abaza AF, Amine AE, Hazzah WA. Comparative study on efficacy of different alcohol hand rubs and routine hand wash in a health-care setting, Alexandria, Egypt. J Egypt Public Health Assoc 2010; 85:273-83.

34. Russo R, Manili L, Tiraboschi G, Amar K, De Luca M, Alberghini $\mathrm{E}$, et al. Patient re-training in peritoneal dialysis: why and when it is needed. Kidney Int Suppl 2006; 70:S127-32.

35. Larson EL. Skin hygiene and infection prevention: more of the same or different approaches? Clin Infect Dis 1999; 29:1287-94. 